\title{
Argentum-quarz solution in the treatment of anorectal fistulas: Is it possible a conservative approach?
}

\author{
Giovanni Tomasello a,f ${ }^{\text {, }}$ Maurizio Bellavia ${ }^{a}$, Francesco Damiani ${ }^{\mathrm{d}}$, Giuseppe Damiano ${ }^{\mathrm{f}}$, \\ Vincenzo Davide Palumbo ${ }^{a, b, f}$, Tiziana Fiorentini ${ }^{b}$, Robero Puleio ${ }^{c}$, Gabriele Spinelli ${ }^{f}$, \\ Provvidenza Damiani ${ }^{\mathrm{e}}$, Silvia Ficarella ${ }^{\mathrm{f}}$, Antonio Bruno ${ }^{\mathrm{f}}$, Attilio Ignazio Lo Monte ${ }^{\mathrm{a}, \mathrm{b}, \mathrm{f}, \mathrm{g}, *}$ \\ ${ }^{a}$ Department of Surgical and Oncologica! Disciplines (DiChirOn), University of Palermo, Italy \\ ${ }^{\mathrm{b}}$ PhD Course on Surgical Biotechnology and Regenerative Medicine in Organ and Tissue Failure, University of Palermo, School of Medicine, Palermo, Italy \\ 'Istituto Zooprofilattico Sperimentale Della Sicilia “A Mirri”, Palermo, Italy \\ ${ }^{\mathrm{d}}$ Department of Emergency, Anesthesia and Intensive Care Unit, University Hospital of Palermo, Palermo, Italy \\ ${ }^{\mathrm{e}}$ Department of Internai Medicine, Cardiovascular and Nephrourological Diseases, University Hospital of Palermo, Palermo, Italy \\ ${ }^{\mathrm{f}}$ School of Medicine, University Hospital of Palermo, Palermo, Italy \\ ${ }^{\mathrm{g}}$ School of Biotechnology, University Hospital of Palermo, Palermo, Italy
}

\section{A R T I C L E I N F O}

\section{Article history:}

Received 12 December 2011

Accepted 10 July 2012

\begin{abstract}
A B S T R A C T
Patients suffering from chronic intestinal diseases (Crohn's disease, Ulcerative Colitis, Indeterminate Colitis) are prone to the development of pyogenic complications. These complications are most commonly in the form of perianal or intraabdominal abscesses and/or fistulas. The treatment of these complications are managed differently but, after an initial treatment based on medical or minimally invasive management, the solution of the pathological condition is always achieved by a surgical procedure.

In the last few years prospective studies have proposed an alternative conservative therapeutic approach based on application of fibrin glue in the healing of patients with fistulas-in-ano.

In this paper we suggest and discuss the therapeutic potential of silver and quarz in the conservative treatment of anorectal fistulas pointing out their role in modulating particular steps of the pathogenetic process which characterizes this pathological condition.
\end{abstract}

(c) 2012 Elsevier Ltd. All rights reserved.

\section{Introduction}

The anal fistulas are acute or chronic suppuration caused by an infection of a gland localized in the Lieberkuhn crypts at the level of the rectum and anal canal. The contact of enteropathogenic bacteria with the mucosa of the crypts, associated with other competing situations (inflammation of the mucosa, constipation), can cause and abscess due to penetration of pyogenic organisms in the tissue-sphincter. Hence the abscess diffuses into the peri-rectal cell-areolar tissue, spreading in adjacent spaces towards perianal skin, after passing through the sphincter apparatus. In addition to infection of a gland at the level of intestinal crypts, another cause of anorectal fistula formation may be the presence of chronic intestinal diseases such as Crohn's disease, Ulcerative Colitis and Indeterminate Colitis. In all cases, the symptoms consist of an inflammation in the site of formation of the fistula, associated with pain and difficulty in defecation. Currently the treatment of fistulas

\footnotetext{
* Corresponding author at: Department of Surgical and Oncological Disciplines, University of Palermo, School of Medicine, Via del Vespro 129, 90127 Palermo, Italy. Tel.: +39 091 6553743; fax: +390916552634

E-mail address: attilioignazio.lomonte@unipa.it (A.I. Lo Monte).
}

requires a surgical approach, aimed to total and accurate removal with different techniques, chosen according to the type of fistula, site of formation, and the specific type of involvement of the sphincter apparatus.

As an alternative to the surgical procedure, a less invasive approach, which involves the injection of fibrin glue or the use of collagen plugs, begins to develop [1-3]. Interestingly it has also been reported the use of silver preparations in the treatment of tracheobronchial fistulas $[4,5]$.

\section{Hypothesis}

As aforementioned the pathogenesis of anorectal fistulas involves an inflammation process caused by enteropathogenic bacteria whose persistence is probably the main reason of the impossibility of healing of the lesion [6].

Intriguingly, published data $[7,8]$ reported that silver-based medical preparations exert both an antimicrobial effect and a role in attenuating the inflammation of the airway in a murine model of asthma [9]. Furthermore both silver-based preparation and quarz can modulate the proliferation rate of fibroblast cells which are the main actors of wound healing process $[10,11]$. 
In light of the aforementioned published data we suggest that anorectal fistulas can be treated in a conservative manner by means of a topic administration of an "argentum-quarz solution" which might contribute to the healing of the lesions through its antimicrobial activity but also modulating the proliferation and differentiation of fibroblast cells.

\section{Evaluation of hypothesis and discussion}

Chronic wounds, as anorectal fistulas infected by enteropathogenic bacteria, show individual combinations of causes leading to the impossibility of a repair and difficulties in standardizing a common care for all patients. The main feature of chronic wounds is the persistence of an inflammatory status characterized by a continuing influx of neutrophils that release cytotoxic enzymes, free oxygen radicals, and inflammatory mediators that cause extensive collateral damage to the tissue. In our opinion, it is reasonable to speculate that within an anorectal fistula healing and destructive processes are out of balance and consequently, by manipulating and counterbalancing these processes, the chronic wound might start to heal. In this regard we think that a solution based on silver and quarz could be a promising therapeutic option. Silver, indeed, could negatively modulate the proliferation of fibroblasts counteracting the infectious action of pyogenic bacteria but, in synergism with quarz, could also stimulate proliferation and differentiation of fibroblasts into myofibroblasts leading to a resolution of the problem [12]; this second effect is probably due to the ability of silver to cause a certain cytotoxicity as we observed an inflammatory infiltration after administration on murine perianal mucosa of an "argentum-quarz solution" (Fig. 1). In particular the perianal mucosa was taken under sedation (Tiletamin + Zolazepan $50 \mathrm{mg} /$ $\mathrm{kg}$ i.m. + Medetomidina $50 \mathrm{mcg} / \mathrm{kg}$ i.m.) and orotracheal intubation $\left(\mathrm{FiO}_{2} 50 \%\right.$, air $50 \%$, isoflurane $3 \%$ ).

In favor of our arguments we report at least two works which pointed out that silver nanoparticles can both cooperate with antibiotics [13] in bactericidal action and improve the tensile properties of the healed skin through a better collagen fibril alignments [14]. In particular Fayaz et al. proposed a mechanism to explain the synergism between silver nanoparticles and ampicillin consisting of their ability to form a core with the antibiotic able to inhibit both the formation of cross-links in the peptidoglycan layer (leading to cell lysis) and the DNA unwinding. Furthermore, in a wound healing murine model, it has been shown that topical delivery of silver nanoparticles was able to reduce the levels of acute-phase

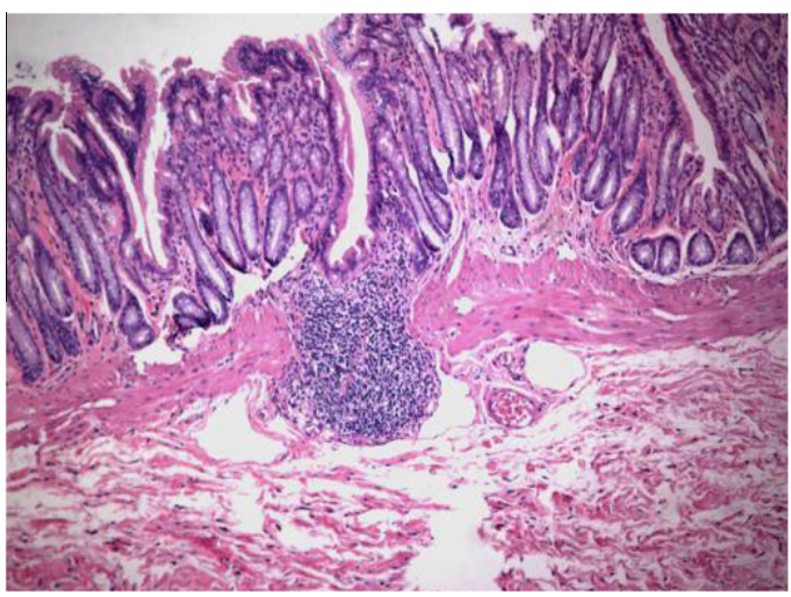

Fig. 1. Histological analysis of a region of perianal mucosa treated with an argentum quarz solution. An inflammatory infiltration (monocytes) takes origin from submucosa tunica and reaches up to mucosa tunica. proteins as hemopexin (Hpx), haptoglobin (Hpg), and serum amyloid protein component $\mathrm{P}$ (SAP) [15].

\section{Conclusions}

The correct repair of a lesion with the "restitutio ad integrum" is a complex process in which inflammation plays a dual role: it indeed, through molecular pathways dependent on proinflammatory cytokines, lead to differentiation of fibroblasts into myofibroblasts with a reparative action [16], but when inflammation persists for a long period becoming chronic the outcome is the process of fibrosis which compromises the normal function of the tissue.

In the case of anorectal fistulas a chronic inflammation could arise because of the presence of enteropathogenic bacteria, so the main therapeutic approach should be directed against this problem. On the other hand inflammation is important to stimulate the repair process consisting of stimulation of proliferation and differentiation of fibroblasts.

We propose that an "argentum-quarz solution", based on silver and quarz, could be a useful, non surgical, therapeutic approach to treat anorectal fistulas because of the aforementioned ability of silver and quarz to reduce bacterial infection but also to modulate proliferation and differentiation of fibroblasts.

\section{Conflict of interest statement}

None declared.

\section{References}

[1] Dudukgian $H$, Abcarian $H$. Why do we have so much trouble treating anal fistula? World J Gastroenterol 2011;17:3292-6.

[2] Buchanan GN, Bartram CI, Phillips RK, et al. Efficacy of fibrin sealant in the management of complex anal fistula: a prospective trial. Dis Colon Rectum 2003;46:1167-74.

[3] Maralcan G, Başkonuş I, Aybasti N, et al. The use of fibrin glue in the treatment of fistula in-ano: a prospective study. Surg Today 2006;36:166-70.

[4] Stratakos G, Zuccatosta L, Porfyridis I, et al. Silver nitrate through flexible bronchoscope in the treatment of bronchopleural fistulae. J Thorac Cardiovasc Surg 2009;138:603-7.

[5] Andreetti C, D'Andrilli A, Ibrahim M, et al. Submucosal injection of the silverhuman albumin complex for the treatment of bronchopleural fistula. Eur J Cardiothorac Surg 2010;37:40-3.

[6] Bjarnsholt T, Klaus Kirketerp-Moller K, Jensen P, et al. Why chronic wounds will not heal: a novel hypothesis. Wound Rep Reg 2008;16:2-10.

[7] Ryu HS, Bae IH, Lee KG, et al. Antibacterial effect of silver-platinum coating for orthodontic appliances. Angle Orthod 2011.

[8] Sahuquillo Arce JM, Iranzo Tatay A, Llácer Luna M, et al. In vitro study of the antimicrobial properties of a silver ion-releasing polyurethane foam. Cir Esp 2011;89:532-8.

[9] Park HS, Kim KH, Jang S, et al. Attenuation of allergic airway inflammation and hyperresponsiveness in a murine model of asthma by silver nanoparticles. Int J Nanomed 2010;5:505-15.

[10] Lee AR, Moon HK. Effect of topically applied silver sulfadiazine on fibroblast cell proliferation and biomechanical properties of the wound. Arch Pharm Res 2003;26:855-60.

[11] Shen FH, Fan XY, Liu BC. Decrease of cyclin D1 and CDK4 protein and their related factors induced by quarz in human embryonic lung fibroblasts. Zhonghua Lao Dong Wei Sheng Zhi Ye Bing Za Zhi 2008;26:391-4.

[12] Liu X, Lee P, Ho C, et al. Silver nanoparticles mediate differential responses in keratinocytes and fibroblasts during skin wound healing. Chem Med Chem 2010;5:468-75.

[13] Fayaz A, Balaji K, Girilal M, et al. Biogenic synthesis of silver nanoparticles and their synergistic effect with antibiotics: a study against gram-positive and gram-negative bacteria. Nanomed Nanotechnol Biol Med 2010;6:103-9.

[14] Kwan KHL, Liu X, To MKT, et al. Modulation of collagen alignment by silver nanoparticles results in better mechanical properties in wound healing. Nanomed Nanotechnol Biol Med 2011;7:497-504.

[15] Tian J, Wong KKY, Ho C, et al. Topical delivery of silver nanoparticles promotes wound healing. Chem Med Chem 2007;2:129-36.

[16] McAnulty RJ. Fibroblasts and myofibroblasts: their source, function and role in disease. Int J Biochem Cell Biol 2007;39:666-71. 